\title{
Garotid Artery Disease - Left vs Right
}

${ }^{1}$ Faculty of Medicine, University "Ovidius" of Constanta

\begin{abstract}
Stroke is a common cause of adult disability and the third cause of death in Western European countries. Carotid disease is a well-known risk factor for ischemic stroke, and this relationship is established. However, only a minority of the population with atherosclerosis will have a stroke.

The aim of these paper is to establish the relation between carotid atherosclerosis and first ischemic stroke. We performed an observational study, including 159 patients with carotid atherosclerosis. Our patients were examined with carotid ultrasound examination and cranio-cerebral computed tomography. We excluded patient with other cause of cerebral ischemia such atrial fibrillation, myocardial infarction, arterial dissection, vasculopathy, neoplasia. We also excluded any kind of transient cerebral ischemia, because of heterogeneity and poor medical documentation.

Despite our efforts to treat this condition, carotid disease remains a powerful risk factor for ischemic stroke.
\end{abstract}

Keywords: atherosclerosis, plaques, carotid artery, left versus right

\section{Ana-Maria Ionescu}

CF Hospital, Constanta

No. 5-7, 1 Mai Bvld., Constanta, Romania

email : anaiulius@yahoo.com

phone: +40723381531

\section{Introduction}

Stroke is a common cause of adult disability and the third cause of death in Western European countries [1].

Atherosclerosis is a chronic, progressive and low inflammatory disease of arteries and the main lesion of this condition is called atherosclerotic plaque. Plaques are characterized by progressive intimal thickening due to accumulations in the arterial wall of lipids, cells, including muscle cells, macrophages, lymphocytes, and minerals as calcium [2]. Carotid stenosis is a narrowing of the arterial lumen, caused by atherosclerosis. Both stenosis and plaques plays key roles for stroke.

\section{Material and method}

Our study comprised 159 patients with carotid atherosclerosis, with an observational design. We assessed our patients with carotid Duplex ultrasonography, using a Philips HD 15 machine, and a 7,5 $\mathrm{MHz}$ transductor in a standardized protocol, according to Mannheim criteria, and a cranio-cerebral 
computed tomography multislice scan was performed. Ischemic stroke was established according to TOAST criteria[3].

We obtained several data as for exploring all carotidal tree, bilateral, including common carotid arteries, internal carotid arteries both bulbar, and distal, and external carotid arteries. Plaques were assessed using the Mannheim criteria[4]. Plaques are focal structures encroaching arterial wall with a thickness more than $1,5 \mathrm{~mm}$. as measured from media-adventitia interface to the intima interface[4].

Carotid intima-media thickness was assesed below the carotid bifurcation, at common carotid artery level, on the far wall, in the first free of plaques region, using validated manual method .The normal range for this sublinical marker of atherosclerosis was within $0.9 \mathrm{~mm}$.[5].

Grading of plaque morphology is based on major classification of Weale Gray, but for practical purpose we established three types of plaques fibrous, calcified, and mixte plaques .

\section{Results}

In our study of 159 patients, 30 patients $(18,87 \%)$ were identified with ischemic large arterial stroke. Carotid plaques were identified in 124 patients (Figure 1).

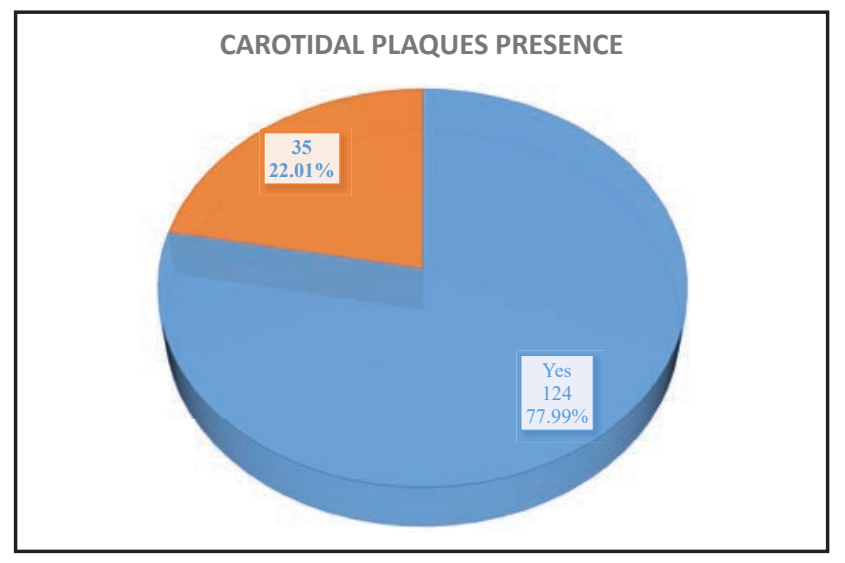

Figure 1 Carotidal plaques presence
The presence of plaques in the carotid arterial system is associated with occurrence of stroke $(p=0,024)$. In the case of patients without plaques, $5.7 \%$ were diagnosed with stroke, while in the group of patients with plaques the proportion of patients diagnosed with stroke is $22,6 \%$ (Figure 2).

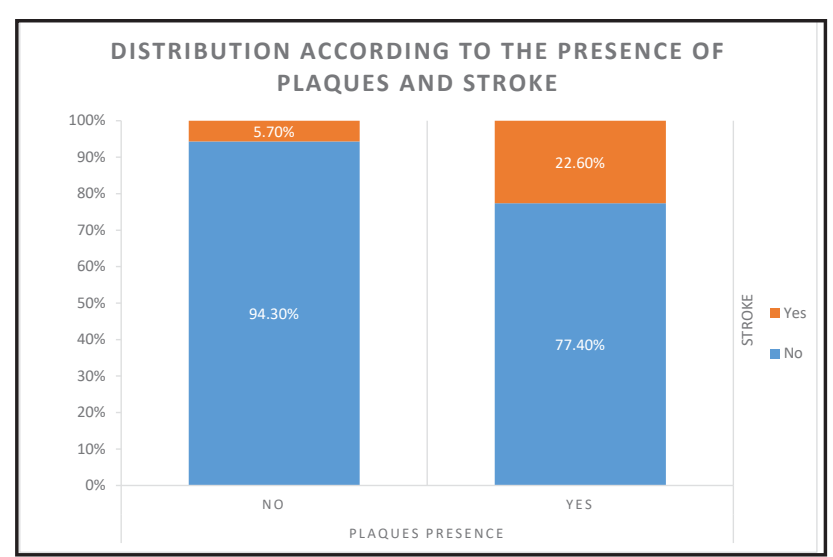

Figure 2 Distribution according to plaques presence and stroke

Atherosclerosis is a systemic, and generally bilateral disease. We obtain similar results for the presence of the plaques at carotidian tree level. We can see that plaques are distributed to all carotid arteries, including pre-bulbar, at common carotid artery level, internal and external carotid arteries. No major differences are between left versus right. According to the gender, we can see there is slight difference for male (Figure 3). Males seems to be more affected by the presence of atherosclerotic plaques at all levels.

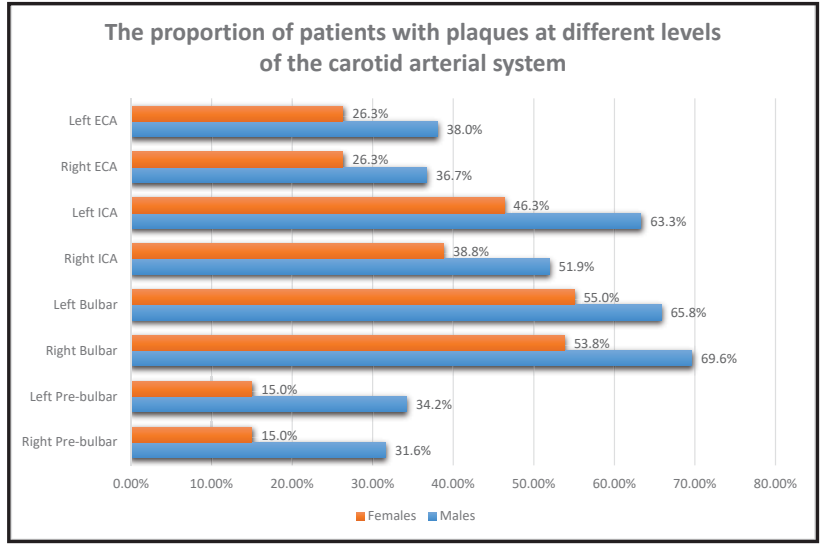

Figure 3 The proportion of patients with plaques at different levels of the carotid arterial system 


\section{Plaques at pre-bulbar level}

From the total number of patients in this study, $28,3 \%$ had atherosclerotic plaques at pre-bulbar level (Table I). The proportion of patients with plaques in the group of patients diagnosed with stroke was $40 \%$ while in the group of patients without stroke was $25,6 \%$. The difference is not statistically significant.

Table I Distribution according to the presence of plaques at pre-bulbar level and stroke

\begin{tabular}{|c|c|c|c|c|}
\hline & & \multicolumn{2}{|c|}{ Stroke } & \multirow[b]{2}{*}{ Total } \\
\hline & & No & Yes & \\
\hline \multirow{4}{*}{$\begin{array}{l}\text { Plaques at pre- } \\
\text { bulbar level }\end{array}$} & Count & 96 & 18 & 114 \\
\hline & $\%$ of Stroke & $74.4 \%$ & $60.0 \%$ & $71.7 \%$ \\
\hline & Count & 33 & 12 & 45 \\
\hline & $\%$ of Stroke & $25.6 \%$ & $40.0 \%$ & $28.3 \%$ \\
\hline \multirow[t]{2}{*}{ Total } & Count & 129 & 30 & 159 \\
\hline & $\%$ of Stroke & $100.0 \%$ & $100.0 \%$ & $100.0 \%$ \\
\hline
\end{tabular}

The symmetry of the presence of plaques at pre-bulbar level

Common carotid arteries, pre-bulbar, are usually bilateral affected (Figure 4). No difference seems to be between right and left and no association with stroke was observed.

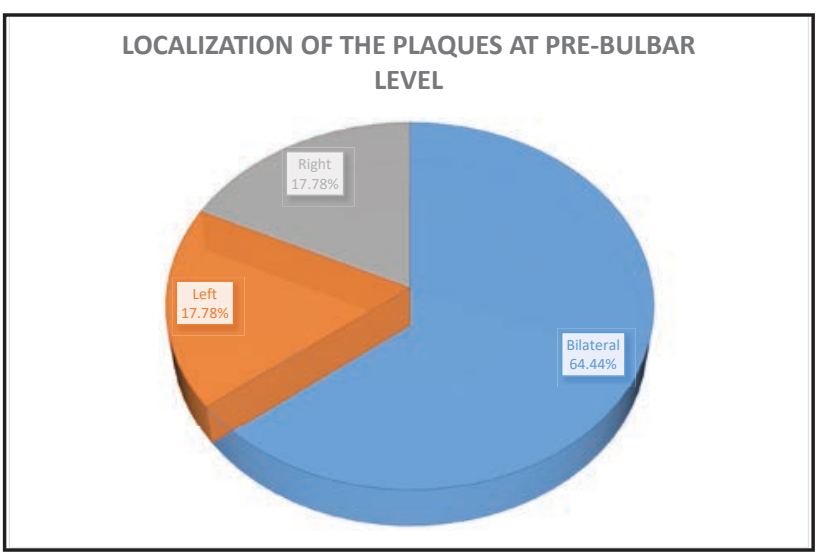

Figure 4 Localization of the plaques at pre-bulbar level

\section{Plaques presence at bulbar level}

Presence of the hallmark of atherosclerosis (plaques) at internal carotid bulb is associated with stroke occurrence $(p=0.02)$ (Table II). $90 \%$ of the patients with stroke had plaques at bulbar level.
Table II Distribution of the patients according to plaques presence at bulbar level and stroke

\begin{tabular}{|c|c|c|c|c|c|}
\hline & & & \multicolumn{2}{|c|}{ Stroke } & \multirow[b]{2}{*}{ Total } \\
\hline & & & No & Yes & \\
\hline \multirow{4}{*}{$\begin{array}{l}\text { Plaques presence } \\
\text { bulbar level }\end{array}$} & at No & Count & 40 & 3 & 43 \\
\hline & & $\%$ of Stroke & $31.0 \%$ & $10.0 \%$ & $27.0 \%$ \\
\hline & Yes & Count & 89 & 27 & 116 \\
\hline & & $\%$ of Stroke & $69.0 \%$ & $90.0 \%$ & 73. $0 \%$ \\
\hline \multirow{2}{*}{\multicolumn{2}{|c|}{ Total }} & Count & 129 & 30 & 159 \\
\hline & & $\%$ of Stroke & $100.0 \%$ & $100.0 \%$ & $100.0 \%$ \\
\hline
\end{tabular}

The symmetry of the presence of plaques at bulbar level is observed, .67,24\% of the patients are bilaterally affected (Figure 5).

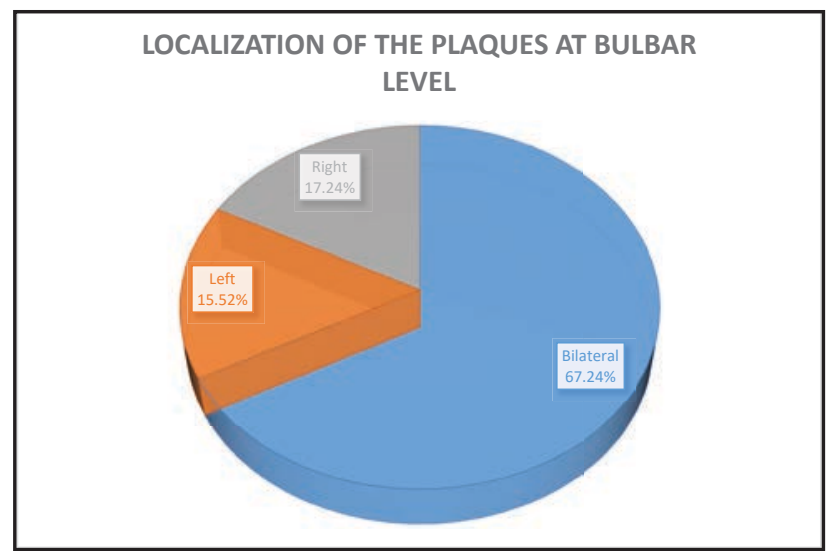

Figure 5 Localization of the plaques at bulbar level

\section{Plaques presence at ICA level}

A statistically significant $(\mathrm{p}=0.001)$ proportion of patients with atheromatous plaques were identified in the group of patients with stroke (Table III).

Table III Distribution of the patients according to plaques presence at ICA level and stroke

\begin{tabular}{|c|c|c|c|c|c|}
\hline & & & \multicolumn{2}{|c|}{ Stroke } & \multirow[b]{2}{*}{ Total } \\
\hline & & & No & Yes & \\
\hline \multirow{4}{*}{$\begin{array}{l}\text { Plaques presence } \\
\text { at ICA level }\end{array}$} & No & Count & 58 & 4 & 62 \\
\hline & & $\%$ of Stroke & $45.0 \%$ & $13.3 \%$ & $39.0 \%$ \\
\hline & Yes & Count & 71 & 26 & 97 \\
\hline & & $\%$ of Stroke & $55.0 \%$ & $86.7 \%$ & $61.0 \%$ \\
\hline \multirow[t]{2}{*}{ Total } & & Count & 129 & 30 & 159 \\
\hline & & $\%$ of Stroke & $100.0 \%$ & $100.0 \%$ & $100.0 \%$ \\
\hline
\end{tabular}

Left side is more affected than right side (Figure 6). The percentage of patients which are affected only on the left size is 2.5 times higher when compared to patients that are affected only on the right size. Almost $70 \%$ of the patients had bilaterally located plaques.

Plaques located at internal carotid artery level are associated with stroke $(\mathrm{p}=0,001)$ 


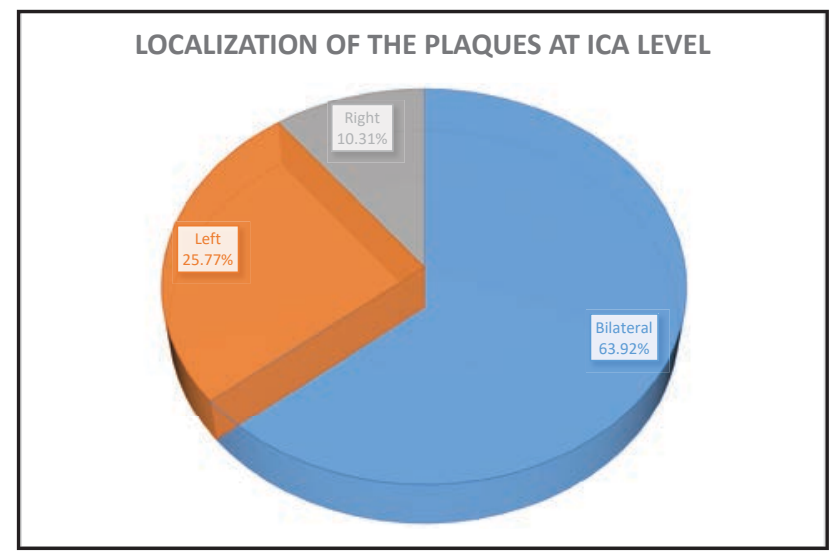

Figure 6 Localization of the plaques at ICA level

\section{Disscussions}

Carotid atherosclerosis is a common disease, and an established risk factor for ischemic stroke. If there are 700. 000 strokes in the United States each year, about one out of four is related to carotid artery disease[6].

Although it is a systemic condition, atherosclerosis is more prevalent for a series of arteries such carotid arteries, coronaries arteries, aorta, or peripheral arteries [7].

Male are having a higher prevalence for carotid plaques and usually they are more exposed to the risk factors (such as smoking) [8].

Atherosclerosis is generally a symmetrical condition. Since our body is exposed equally to the same risk factors, we expect that atherosclerotic hallmarks as plaques might be present in the same way. A few studies study this asymmetry. For example, a study based on post mortem examination of 50 pairs of carotid from donors shows that volume of the wall and composition was the same in the right and in the left, after MRI studies [9].

Other study showed a higher prevalence of plaques for left carotid artery (internal carotid artery). In this study, carotid MRI scanning was performed in 1414 stroke-free participants, older than 45 years.
$85 \%$ of the participants had bilateral carotid plaques.

Unilateral plaques were twice more prevalent on the left than on the right side [10]

Left carotid plaques are related with stroke occurrence. That seems to be related with more vulnerability of plaques on the left side.

Vulnerable plaque means a plaque which is having a lipid core and is covered by a thin fibrous cap prone to rupture. The cycle of rupture and healing is the main mechanism of arterial stenosis both in heart disease and stroke [11].

One possible explanation for this increased vulnerability could be related with carotid artery anatomy and hemodynamics. The left carotid artery arise from aortic arch, and on the right side the carotid branch is arising from brachiocephalic artery, so on the left side the pressure could be higher. Geometry of carotid artery, including hemodynamics of flow divider carotid area are import for stroke occurrence [12].

\section{Conclusions}

Plaques burden development is a heterogeneous process, usually with bilateral involvement. Although atherosclerotic plaques tend to develop to certain sites, our conclusions shows that could be a connection between different location of vascular carotid tree and ischemic stroke.

\section{References}

1. The Internet Stroke Center. Stroke Statistics. from http://www.strokecenter.org/patients/ about-stroke/stroke-statistics/

2. Nicolaides, A., Beach, K.W., Kyriacou, E. \& Pattichis, C.S. (2011). Ultrasound and Carotid 
Bifurcation Atherosclerosis: Springer London.

3. Adams, H.P., Jr., Bendixen, B.H., Kappelle, L.J., Biller, J., Love, B.B., Gordon, D.L. \& Marsh, E.E., 3rd. (1993). Classification of subtype of acute ischemic stroke. Definitions for use in a multicenter clinical trial. TOAST. Trial of Org 10172 in Acute Stroke Treatment. Stroke. 24(1), 35-41.

4. Touboul, P.J., Hennerici, M.G., Meairs, S., Adams, H., Amarenco, P., Bornstein, N., Csiba, L., Desvarieux, M., Ebrahim, S., Hernandez Hernandez, R., Jaff, M., Kownator, S., Naqvi, T., Prati, P., Rundek, T., Sitzer, M., Schminke, U., Tardif, J.C., Taylor, A., Vicaut, E. \& Woo, K.S. (2012). Mannheim carotid intima-media thickness and plaque consensus (2004-20062011). An update on behalf of the advisory board of the 3rd, 4th and 5th watching the risk symposia, at the 13th, 15th and 20th European Stroke Conferences, Mannheim, Germany, 2004, Brussels, Belgium, 2006, and Hamburg, Germany, 2011. Cerebrovasc Dis. 34(4), 290296. doi: $10.1159 / 000343145$

5. Corrado, E., La Greca, C., Buccheri, D., Toia, P., Russo, R., Carita, P., Novo, G. \& S., N. (2011). Subclinical atherosclerosis, inflammation and events. E-journal of the ESC Council for Cardiology Practice. 9(16-18).

6. Vascular Surgery. Carotid Artery Disease and Stroke. Areas of Expertise. from http://www.surgery.usc.edu/vascular/ carotidarterydiseaseandstroke.html

7. What is Atherosclerosis? (2016). Health Topics. from http://www.nhlbi.nih.gov/health/healthtopics/topics/atherosclerosis/

8. Tromba, L., Tartaglia, F., Blasi, S., Giuliani, A., Carbotta, S., Kiltzanidi, D., Cavaiola, S., Tortorelli, G., Carbotta, G. \& Pelle, F. (2015). Is Carotid Stenosis in Women a Gender-Related Condition? Journal of Women's Health. 25(4), 348-354. doi: 10.1089/jwh.2015.5300

9. Adams, G.J., Simoni, D.M., Bordelon, C.B., Jr., Vick, G.W., 3rd, Kimball, K.T., Insull, W., Jr. \& Morrisett, J.D. (2002). Bilateral symmetry of human carotid artery atherosclerosis. Stroke. 33(11), 2575-2580.

10. Selwaness, M., van den Bouwhuijsen, Q., van
Onkelen, R.S., Hofman, A., Franco, O.H., van der Lugt, A., Wentzel, J.J. \& Vernooij, M. (2014). Atherosclerotic plaque in the left carotid artery is more vulnerable than in the right. Stroke. 45(11), 3226-3230. doi: 10.1161/strokeaha.114.005202

11. Vulnerable plaque. (n.d.) Segen's Medical Dictionary. from http://medical-dictionary. thefreedictionary.com/Vulnerable+Plaque

12. Phan, T.G., Beare, R.J., Jolley, D., Das, G., Ren, M., Wong, K., Chong, W., Sinnott, M.D., Hilton, J.E. \& Srikanth, V. (2012). Carotid Artery Anatomy and Geometry as Risk Factors for Carotid Atherosclerotic Disease. Stroke. 43(6), 1596-1601. doi: 10.1161/strokeaha.111.645499 